\title{
Demonstration Process Skills: From Explanation to Validation in a Precalculus Laboratory Course
}

\author{
Jorge Fiallo ${ }^{1 *}$, Angélica Mayerly Velasco Méndez ${ }^{1}$, Sandra Evely Parada Rico ${ }^{1}$ \\ ${ }^{1}$ Universidad Industrial de Santander, COLOMBIA
}

Received 1 July 2021 - Accepted 22 September 2021

\begin{abstract}
We present results of a research developed with first semester students from a Colombian Public University based on classroom intervention in a precalculus laboratory course mediated by an interactive mathematical software. We characterize and exemplify the cognitive skills of explanation, justification, argumentation and validation, using a methodological tool of analysis that integrates the ckç model of Balachef and Margolinas to Toulmin's model. This tool allows us to identify some elements that characterize each of these skills and allow us to offer a structure of analysis that we present as a proposal for the design of activities in research, based on classroom interventions that promote the development of demonstration skills.
\end{abstract}

Keywords: argumentation, cognitive demonstration skills, explanation, justification, precalculus, validation

\section{INTRODUCTION}

At the beginning of the first university courses, students are expected to have mathematical competencies, such as those indicated in the Mathematics Curricular Guidelines (MEN, 1998) and the Basic Standards in Mathematics Competencies (MEN, 2006). However, in the university reality, professors believe that "students do not have the necessary knowledge to learn calculus".

"[...] what is found in the calculus scenario is a lack of understanding of the concepts, poor handling of reasoning, apart from a not very solid algebraic competence in the resolution of new problems, and on the part of the teachers, the frustration caused by the certainty that they have not understood us" (Neira, 2000, p. 88).

In the Basic Standards of Mathematical Competences, it is stated that Being mathematically competent means:

- "Formulating, posing, transforming and solving problems from everyday life situations, from other sciences and from mathematics itself.

- Using different representation registers or symbolic notation systems to create, express and represent mathematical ideas.
- Using argumentation, proof and refutation, example and counterexample, as means of validating and rejecting conjectures, and moving towards demonstration.

- Mastering mathematical procedures and algorithms and knowing how, when and why to use them in a flexible and effective manner" (MEN, 2006, p. 51).

Since the first semester of 2013, the Universidad Industrial de Santander has been implementing a precalculus laboratory course, whose purpose is to help students develop "variational thinking"; understood as "a conceptual field that involves concepts and interstructured and linked procedures that allow one to analyze, organize and mathematically model situations and problems of both the practical activity of man, as well as those of the sciences and mathematics itself where variation is found as their substratum" (MEN, 1998, p. 72).

The course encourages an active process of problemsolving, involving reasoning and demonstration, communication, representation, and the use of mathematical procedures and algorithms. In addition, technology is incorporated as key to the production of meaningful learning, around the two central ideas of the Calculus of Variation and Accumulation, which allow 


\section{Contribution to the literature}

- This article presents a characterization of the demonstration skills, pointing out and explaining with examples, the structural and referential elements of each of the proposed skills.

- The article shows an example that addresses the need for research-based interventions in the classroom, for the case of teaching and learning the demonstration in a differential calculus course. The course was developed during the COVID-19 pandemic through technological and methodological adaptations.

- The article provides theoretical and methodological contributions for the teaching of the demonstration in a higher education course.

the student to establish a mathematical level relevant to the requirements of the Differential Calculus course (Fiallo \& Parada, 2018).

In the design of the pre-calculus course-laboratory, activities have been implicitly included that promote the development of processes through problem solving and guiding questions, which are answered in the interactive mathematical software GeoGebra. In turn, the research project of the Vice-rectory for Research and Extension of the Industrial University of Santander "Study of the mathematical processes developed by students in a precalculus course mediated by interactive mathematical software" (Research project 2425, VIE-UIS, 2018), was proposed with the aim of providing information for a better understanding of the mathematical processing in the context of a pre-calculus laboratory course mediated by GeoGebra in order to answer the question: What mathematical processes skills are developed in a precalculus course-laboratory mediated by interactive mathematical software?

As a result of this and other investigations, cognitive skills were proposed for each of these processes (Fiallo \& Parada, 2018), which have served as a guide for the teachers of the course to promote the development of these skills, so that students achieve greater success in the Differential Calculus course. In particular, for the demonstration process, the skills of explanation, justification, argumentation and validation have been proposed; besides considering convince as one of the functional characteristics of the demonstration. The character of conviction is specific to the demonstration, i.e. it is built with the objective of making what is affirmed irrefutable, it is addressed to a mathematical community, which recognizes the validation value and consequently the conviction value of the demonstration (Fiallo, 2011, p. 78).

In this paper, we present results of a research based on a classroom intervention (Stylianides \& Stylianides, 2013, 2017), with close collaboration between teachers and researchers, addressing problems of variation, change, approximation and trend, and analyzing students' written productions and video recordings, in order to characterize the cognitive skills achieved by students participating in a precalculus laboratory course in relation to the process of mathematical proof. This objective responds in part to the research question posed above.

For the analysis of the productions, the analytical tool proposed by Pedemonte (2005) was used, based on the incorporation of the ckç model (Balacheff \& Margolinas, 2005), in Toulmin's schemes (Toulmin, 2003), and the characterization of demonstration given in Fiallo (2011). The intervention was carried out in the second semester of 2020, with 30 incoming students to science and engineering majors at university (16 - 19 years old), who presented a characterization test on variational thinking, which placed them at risk to succeed in the Differential Calculus course. The course was carried out during sessions of four hours each, stretching over a period of fifteen days, in which the aim was to work and reinforce the mathematical processes.

\section{THEORETICAL BASIS}

Taking into account that a classroom intervention (Stylianides \& Stylianides, 2013) aims to improve classroom practice by the design of such interventions; and also to deepen the understanding of the ways of acting on students' learning problems through teaching, we present an intervention that has theoretical and methodological support in the ideas of the book "Dynamic study of change and variation: Precalculus course mediated by GeoGebra" (Fiallo \& Parada, 2018). These ideas are based on some reflections on the historical and epistemological evolution of the objects of study of the Differential Calculus course and the conceptualization that has been achieved from the theoretical and empirical study of calculus learning problems. We use these ideas as the basis to achieve the close collaboration between teachers and researchers and we will try to synthesize in the following sections, complementing them with other research results, focusing the attention on the skills of the demonstration process.

\section{Reasoning About Variation Phenomena}

The search for solutions to the problems of mechanics and geometry led several of the great mathematicians to search for patterns, regularities and generalization through observation, experimentation and intuition, so that later other great mathematicians organized and systematized the ideas around definitions, axioms and 
theorems. Several of the concepts worked on in the early days of calculus were assumed to be true because they validated the ideas and conjectures raised by intuition, experimentation and induction. However, after the axiomatization of the ideas of calculus and the era of modern mathematics, intuition and induction took a back seat, giving way to an exaggerated emphasis on rigor, which led to the tension between intuitive, inductive, abductive and deductive reasoning with the due consequences in the teaching of mathematics that we have already pointed out as stated by Moreno (2014):

The tension between intuitive, inductive and purely deductive reasoning continues gravitating today in the educational milieu. Today, let us reiterate, the words of René Thom remain as valid as ever: The real problem facing teaching is not that of rigor but the problem of the development of the meaning and existence of mathematical objects... if there is a choice between rigor and meaning, I certainly choose meaning (p. 107).

Deductive reasoning is a way of thinking that arises from the need to ensure the validity of a statement and the mathematical way to achieve this, is through deductive demonstration, however, as Polya puts it:

All our knowledge, apart from mathematics and the logic of demonstration, consists of conjecture. We secure our mathematical knowledge by demonstrative reasoning, but we support our conjectures by plausible reasoning. Demonstrative reasoning is certain, definitive, and beyond controversy. Plausible reasoning is haphazard, debatable, and provisional (Polya, 1966, p. 13).

On the other hand, from the didactics of mathematics it has been proposed that the role of a proof is not only to show the validity of a theorem, but also to show the reasons for this validity. A demonstration should make it possible to understand the theorem, not only to say what is true but also to say why it is true.

With these ideas in mind, we consider demonstration from a broad perspective, as the process that includes all the arguments put forward by students to explain, justify, argue or validate with a view to convince themselves, other students and the teacher of the veracity of a mathematical statement (Fiallo, 2011, p. 81). This characterization of demonstration allows considering several types of demonstration, product of intuitive, inductive or empirical, deductive and abductive reasoning.

The skills required in the process of reasoning about variation phenomena correspond to explaining, justifying, arguing and validating. These skills are promoted when students are asked in the statement the question why, and when they are asked to give the answer to the activity and explain the procedure.
Students have to write and expose the solution to peers and to the teacher, describing the object of knowledge with clear words or examples, expressing the reason for the solution and the procedure performed, in order to make the object of knowledge intelligible to others. When students exchange ideas and submit them to reflective critique, they sharpen their ability to criticize and follow the arguments of others. They also develop clearer and more coherent communication of understandings through verbal explanations, notations and mathematical representations appropriate to explain ideas about change, variation, interdependence, approximation and trend (Fiallo \& Parada, 2018).

\section{Cognitive Demonstration Skills}

In this section cognitive skills are considered as:

\begin{abstract}
"The mental operations that result from the coordination of actions aimed at achieving an objective linked to a branch of institutionalized knowledge. In the same way, we consider as cognitive skill the actions that an individual can develop to interact with an object that he can identify as an object of study by himself "(Rueda, 2016, p. 29).
\end{abstract}

According to this definition and the definition of demonstration, which comprises all arguments put forward by students to explain, verify, justify or validate with a view to convince themselves, other students and the teacher of the veracity of a mathematical statement (Fiallo, 2011, p. 81), we propose the following cognitive skills of demonstration to be incorporated into the precalculus laboratory course.

\section{Explanation skill}

Explaining implies providing clarity about a given phenomenon or situation. From Mathematics Education, Balacheff (2000) considers explanation as the primary idea from which proof and demonstration are derived. For his part, Duval (1992-1993) states that explanation is a reflective activity in relation to another, i.e., it becomes a means to interweave or unite ideas, giving one or more reasons for understanding data, a phenomenon or a result. The National Council Teachers of Mathematics (NCTM, 2003) states that explanation has to do with giving clarity to the answers of a given procedure, using increasingly rigorous language as the school level progresses. When the purpose of the class is for students to demonstrate the ability to explain, they are expected to express orally and in writing, using mathematical language, the strategies, predictions, conjectures and results when faced with the resolution of a mathematical problem. 


\section{Justification skill}

Justifying consists of producing reasons or arguments, establishing relationships between them and examining their acceptability (Fiallo \& Parada, 2018, p. 73). Justification refers to the activities and processes through which an assertion is supported, the reason for a process is stated, and a conclusion is admitted or refuted by means of relevant reasons such as carrying out a procedure, proposing a certain strategy, and using a counter example to achieve conviction and adherence to its thesis (Bautista, 2017).

Jorba et al. (1998) state that justifying is "producing reasons or arguments, establishing relationships between them and examining their acceptability with the aim of modifying the epistemic value of a thesis in relation to the body of knowledge in which the knowledge that is the object of the thesis is included" (p. 48).

Rigo et al. (2011) use the term justification to refer to all kinds of argumentative resources given in mathematics classes to support statements with mathematical content and to promote a degree of adhesion and conviction towards it. Justification usually has two purposes:

- Epistemological purpose, which consists of explaining or substantiating a mathematical truth,

- Psychological purpose, which consists of the interlocutor achieving some learning.

\section{Argumentation skills}

Taking into account the functional characteristics of argumentation, Pedemonte (2002), states that argumentation in mathematics is:

A rational justification, visible in the form of reasoning (inductive, abductive, deductive).

From the epistemological point of view, argumentation in mathematics is developed when someone wants to convince (himself or others) of an assertion; taking into account that "persuade" and "convince" have different meanings. Convincing implies modifying opinions and confidences by appealing to rationality, while persuading seeks consent without appealing to rationality. Convincing implies persuading but persuading does not imply convincing. In the case of a mathematics class, the mathematical community may be the teacher, one or more students, or the whole class.

The field of an argumentation in mathematics delimits the criteria of validity. For example, the validation axioms of an argumentation in geometry are different from the axioms used in an argumentation in algebra.

\section{Validation skill}

According to González and Rodríguez (2006), validation is a complex and central skill in mathematics, and its mastery allows students to gradually acquire autonomy in their learning. Validation requires the student to give reasons, to justify their assertions and be willing to defend them with the intention of convincing the peer group.

Validation brings into play sharing where the decisions taken are debated and the need to guarantee their validity or to denounce the fact that one does not agree with the arguments of the other is expressed. Validation is characterized by the desire to give strength or firmness to what has been concluded, to make it valid. In mathematics, validating a statement means attesting to its truth within a mathematical theory. In a sense, proof, like argumentation, aims at finding the reasons for what is "true" (Pedemonte, 2002).

On the other hand, Margolinas states that validation need not necessarily be linked to proof.

"For the mathematician and for the educator, the term validation often evokes the problem of proof. We do not think that the point of view of validation is completely included in that of proof. ... we are interested in what generally happens at the end of a mathematical problem-solving task, that is, at the moment when we try to know whether the result obtained is appropriate to the problem posed. The validation point of view begins then by examining the end of the resolution" (Margolinas, 2009, p. 22).

These skills are evidenced in the actions performed by the students in the resolution of the problems posed, as we will see in the analysis and exemplification section, and in the characterization of these skills.

\section{DEMONSTRATION COGNITIVE SKILLS ANALYSIS TOOL}

We present a data analysis model that allows us to better visualize the skills used by students to solve the problems posed. This model is based on the structural characteristics of an argument proposed by Toulmin (2007), and the analysis of the reference system proposed by Balacheff and Margolinas (2005). According to Pedemonte $(2002,2005)$ Toulmin's model allows us to transform the process of solving a problem into a concatenation of argumentation steps, but it is not sufficient for the purpose of performing a cognitive analysis, so a tool is needed to consider the reference system of the argumentation and to consider the aspects related to the student's knowledge that are at stake during the resolution of a problem. This tool is offered by the $\mathrm{CK} \$$ model. 


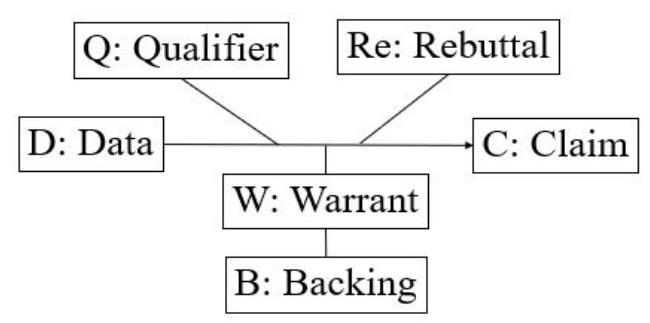

Figure 1. Scheme of Toulmin's model

\section{Toulmin's Model}

An argument in Toulmin's model is composed by a scheme (Figure 1) formed by (Pedemonte, 2005, p. 321322). A claim (C) or conclusion statement that the speaker intends to justify; some data (D) that serve the speaker to justify the statement $\mathrm{C}$; a warrant $(\mathrm{W})$ that offers a rule; a general principle capable of serving as a basis for this inference, of acting as a bridge between $\mathrm{D}$ and $\mathrm{C}$.

The first step in the argument is the expression of a point of view; it is the conclusion, the objective of the argument. The argumentation must support that statement. The argumentation that is made to justify the claim is supported by those data.

To go from the data to the claim, a "warrant" is necessary to legitimize this step. A warrant is a rule or a general principle that authorizes the launching of a bridge between data and claim. This warrant is the part of the argument that establishes the logical connection between the data and the claim. It is the reason for the acceptance or refutation of the argument. It is the point that can be refuted by the auditor. If the argument is not accepted, it is precisely the warrant that is criticized.

In general, rules and data do not allow inferences to be made with an absolute degree of certainty. For this reason, a qualifier $(\mathrm{Q})$ is used, which specifies the force with which the linkage of data to the inference allows the statement to be reached. The qualifier of the argument may not be explicit, but the argument will always be qualified as "true", "probably true", "probable", etc.

It is possible that particular circumstances may prevent the application of the inference to the field of data. The argumentative scheme provides for the restriction of its statement. If there are exceptions to the statement, the force of the warrant decreases. The conditions of the exceptions or rebuttal (Re) are then taken into consideration. The warrant can be questioned. It is then necessary to back it up, to support it with some justifications, which constitute the backing (B).

\section{The cK\$ Model}

The $\mathrm{CK} \$$ model is a methodological tool proposed by Balacheff (2005) for the analysis of the knowledge mobilized by students in solving a problem. In the model, a conception is characterized by a quadruple $(\mathrm{P}$, $\mathrm{R}, \mathrm{L}, \Sigma)$, composed of a problem set (P); a set of operators

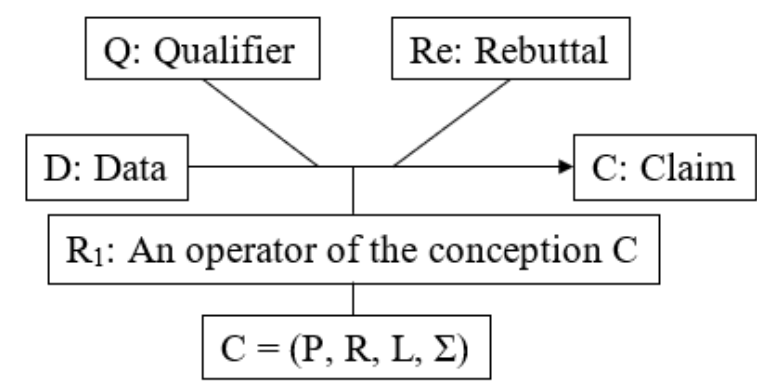

Figure 2. The structure of Toulmin's model integrating the cK\$ model

(R); a representation system (L); and a control structure $(\Sigma)$ (Balacheff \& Margolinas, 2005, p. 82 - 83).

An operator is what allows the transformation of problems. Operators are visible in students' productions and behaviors. A representation system (linguistic or not) allows the expression of problems and operators. Representations allow the expression of controls, actions and problems, for anticipation and validation.

The control structure provides and organizes the functions of decision, choice, validity and appropriateness of action (Balacheff \& Margolinas, 2005, p. 84).

\section{The cK\$ Model in Toulmin's Model}

The students' conceptions that make it possible to construct a conjecture, constitute the basis of the argumentation. Their mobilization makes it possible to construct the argumentative process. The structure of Toulmin's model is as follows by integrating the $\mathrm{cK} \Phi$ model into it where the backing (B) is replaced by the students' conceptions and the warrant by the operators of the conception (Figure 2).

\section{RESEARCH METHODOLOGY}

In this section, we present results of a research based on a classroom intervention (Stylianides \& Stylianides, 2013), namely, the precalculus laboratory course mediated by interactive mathematical software (Fiallo \& Parada, 2018), the student sample, and our procedure for analyzing student productions.

It is important to point out that in the transcriptions of the dialogues between students and teacher will have the following notation: Stu refers to the students' interventions and $T$ to the teacher's interventions.

\section{Pre-calculus Laboratory Course}

The problems proposed in the course are based on the study contents of Calculus with contextual situations (problems for each 4-hour session), with the objective of generating spaces where students work as if they were mathematicians. 
The didactic component for the design of the activities was proposed taking into account the following phases:

- Free exploration: at the beginning of the activity, a problem related to the topic to be studied is posed for the student to try to solve individually or in pairs without the use of the software.

- Socialization of the results: the teacher promotes the participation of the students so that they communicate their solutions, discuss them in group, clarify doubts and mainly, correct errors, review concepts and promote the need to offer a mathematically valid solution to the problem posed.

- Targeted exploration: the exploration of a file in GeoGebra is the starting point so that, through exploration and guidance guided by questions. Initially the student works individually, using the different tools of the software, can find answers to the problem, make conjectures and mathematically justify the results visualized in the different representations offered by the software, through its different views.

- Explanation: discussion with the students and the teacher is suggested, the participation of the students is promoted so that they can propose their own solutions and discuss them with the group in general and with the teacher. The teacher's role should be that of a promoter of debate, reflection and discussion of the ideas presented, in such a way that the construction of knowledge and the development of mathematical processes are achieved.

- Free orientation: a new problem is posed to apply what has been learned. A challenging task, where the student must apply what he/she has learned, but not in a mechanical way.

\section{Intervention}

The intervention has been carried out since 2013 with incoming students to science and engineering majors at university (16 - 19 years old), who have presented a diagnostic test on variational thinking, which places them at risk to succeed in the Differential Calculus course.

For the present article, the productions of the students of the second semester of 2020 were taken into account. The intervention was implemented on the GeoGebra Virtual Classroom (GVC) platform, under the remote attendance modality. The Zoom platform was used for the synchronous meetings of 4 hours per day, due to the worldwide confinement experienced as a result of COVID-19.

The precalculus course workshops were set up in the groups module and in the book module of the GVC. The groups module allows the creation of a virtual classroom to propose research tasks to students, in which simulations and constructions can be published, allowing continuous individual and group feedback, constant communication with the teacher, sending answers, adding comments and uploading images. For the purposes of the research, this option was used in the individual work moments (free exploration, free orientation). Similarly, in the GVC, students have the possibility of interacting synchronously through the book option, which allows the teacher to instantly see the answers given by the students to the respective problems posed, and also helps to identify whether all students have accessed the problem and are working, since those who are not working, will have a blank answer space.

The intervention was carried out with the close collaboration of teachers and researchers, with whom reflection and training sessions were held (before and during the development of the course), in which the theoretical and methodological elements proposed in Fiallo and Parada (2018) were discussed. The intervention from which the data for the study reported here were derived, was guided by the second author of this document, who was a teacher of the course. At the time the course was developed, she had previous training and experience received from undergraduate studies, which is now enriched by her vision as a researcher in training.

\section{EXPLANATION AND VALIDATION SKILLS ACHIEVED IN THE PRE- CALCULUS LABORATORY COURSE}

Next, we present some examples of each of the skills analyzed, we present the outlines of the arguments made, we highlight dialogues between students and teacher, and finally we focus on the main elements that allow us to make the proposed characterization.

\section{Explanation Skills}

Explanation skills are promoted when students are asked to give the answer to the activity and explain the procedure. Students have to write and explain the solution to peers and the teacher, describing the object of knowledge with clear words or examples, expressing the reason for the solution and the process performed, in order to make the object of knowledge intelligible to others. We present the first task proposed in workshop 4 (Figure 3).

The following is an example of the explanation skill developed by one of the students (Stu1) when solving the problem. In Figures 4 and 5 we give evidence of the first analysis performed by the student, who in his reasoning considers that the problem is solved by means of a linear model. However, he himself realizes that due to the high amount of medicine that remained in the body, the model is not linear. 
Problem 1: Filtration of the medication problem

A player hit her knee playing

volleyball and her doctor prescribed an anti-inflammatory to reduce swelling. She had to take 2 tablets of 220 milligrams every 8 hours for 10 days. Her kidneys filtered $60 \%$ of the medication from her body every 8 hours.

1.1Based on the above, answer.

How much of the medication was left in her circulatory system at the end of the 10 days? Justify your answer.

\section{$\underline{A}$ \\ $f_{x}$}

Figure 3. Filtration of the medication problem

\begin{tabular}{|l}
$\underline{A} \begin{array}{l}\text { To know how much medication, he took in } 8 \text { hours multiply } 8 \times 220=1760 \text {, then we convert the } 10 \text { days to } \\
f_{x}\end{array}$ \\
$\begin{array}{l}\text { hours which is } 240 \text { hours divide by } 8 \text { to know how many doses she took and that's } 30 \text { doses, we know that } \\
\text { milligrams she took in the } 10 \text { days. } \\
\text { It tells us that } 60 \% \text { of the medication is leaked so we multiply by } 0,4 \text { the amount received and that gives us } \\
=21.120 \text { milligrams that remain in the body. (linear) (but I think it's not linear :'v) }\end{array}$ \\
\hline
\end{tabular}

Figure 4. Stu1's first response to activity 1 from workshop

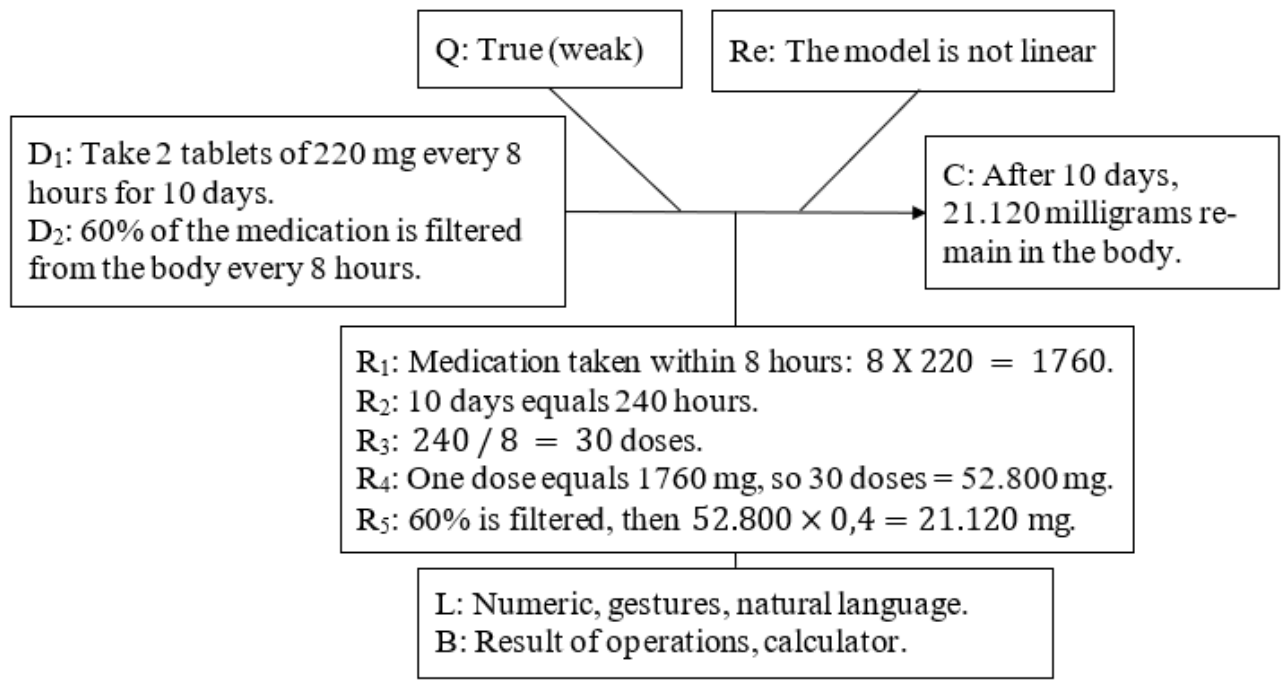

Figure 5. Scheme of the process of explanation of statement 1

The student verbally states that this excess of medication in the player's body could cause her death by overdose. This situation led to a group discussion and to the restatement of the conclusion statement.

Stu2: Teacher, is it possible to find a dose in terms of days, or would it be to find a formula taking into account the dose?

Stu1: Well, I think that it is not per day. In this case it would be a formula in terms of the dose because the player is taking medication and filtering $40 \%$, but this is not done at the end, it is done before the intake. The remaining medication depends on the dose.

Stu2: Yes, I also consider the same thing. In terms of the days, it would not be convenient because each day is different and depends on what is left in the body, i.e., the previous dose.

The above dialogue led to a rethinking of the procedure previously performed by the student (Figure 4). The new interpretation is shown in Figure 6.

The student restates the solution by taking some particular examples, which allow him/her to arrive at a general equation (Figure 6), this being one of the fundamental activities to develop the ability to explain, since from these examples a pattern is identified, which leads to the use of different representations of the same mathematical object of study, thus contributing to seek strategies and procedures to make the solution to the problem known to his/her peers through a clear language. 


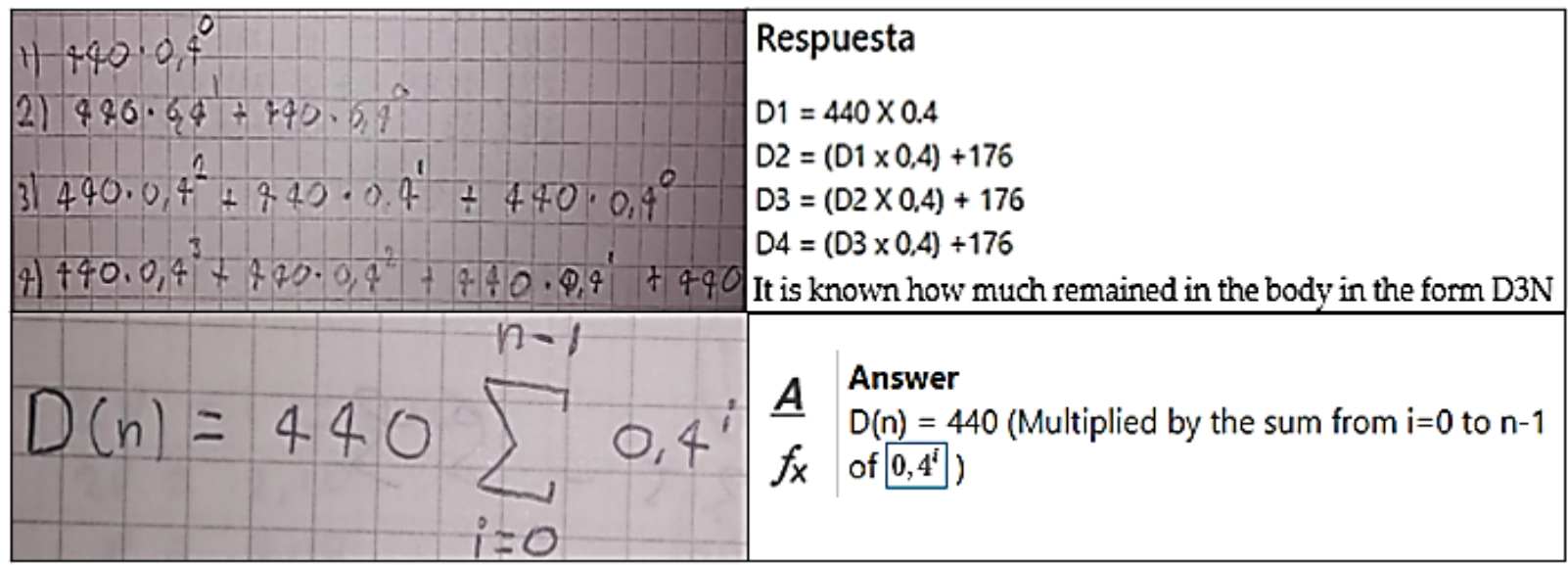

Figure 6. Stu1's response

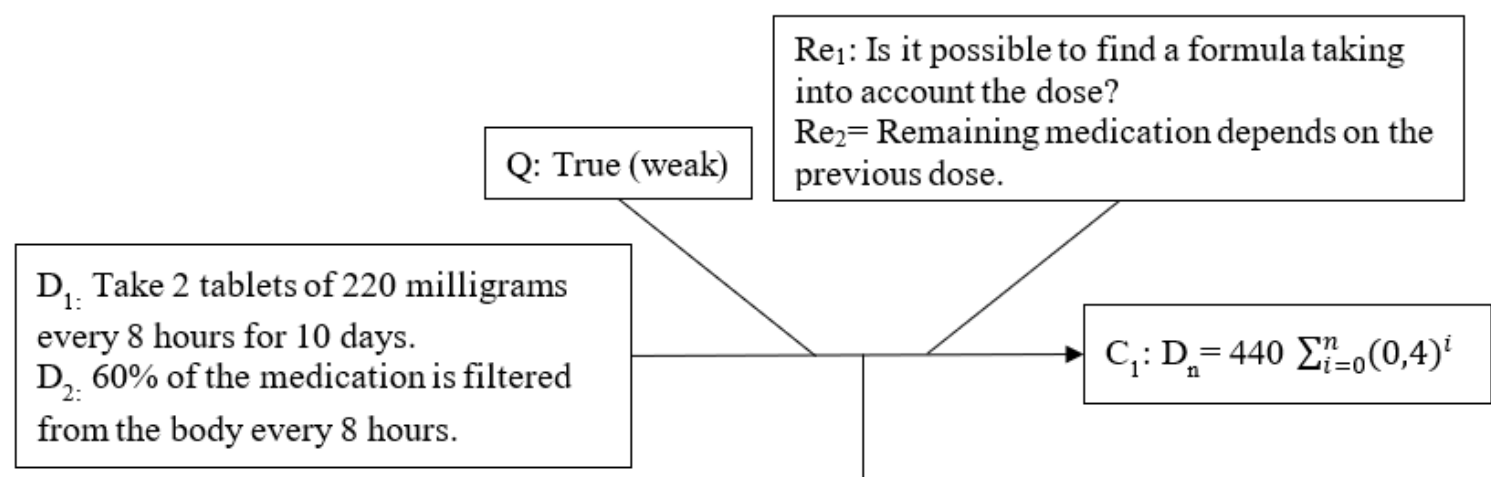

$R_{1}$ : If $60 \%$ is filtered out, $40 \%$ of the medication remains, equals to 0,4

$\mathrm{R}_{2}: \mathrm{D} 1=440 \times(0,4), \mathrm{D} 2=440+(440 \times 0,4) \ldots$

$R_{3}$ : Successive repetition of the value $440 \times 0,4$

$\mathrm{R}_{4}$ : Arithmetic procedures.

L: Numerical, gestural, natural language, algebraic

$\sum$ : Calculator results, test with the formula (summation) for each case.

Figure 7 . Scheme of the explanation process of statement 1 from the new solution

In the explanation phase, where the discussion of the results is promoted, the student (Stu1) describes: "In the first intake the player ingests 440 milligrams of medication and $60 \%$ of this is filtered, that is, $40 \%$ remains in the body", therefore he writes $D_{1}=440 \times$ 0,4 referring to the dose that remains in the body; he also mentions that the first dose is 440 , which implies that the second dose is $440+(440 \times 0,4)$. The second dose is 440 since it refers to the new dose plus the remaining dose (D1). The next dose would be $\left(\mathrm{D}_{2} \times 0,4\right)+176+$ $440=(440 \times 0,4 \times 0,4)+(440 \times 0,4)+440=$ $440 \times 0,4^{2}+440 \times 0,4+440=(440)\left(0,4^{2}+0,4+1\right)$.

When Stu1continued this process, he observed that each time he had to multiply by 0,$4 ; 60 \%$ of the medicine was filtered again, so that, by continuing this reasoning repeatedly, he identified that the value $(0,4)$ was constantly repeated in each of the doses taken, which led to the restructuring and generalization of the problem through the procedure carried out in Figure 6, which subsequently allowed the use of the summation formula (already known from school).

After the previous intervention, to corroborate that the solution given by Stu1 was feasible, the students took some examples, replaced them in the formula and compared them with the procedure performed term by term, i.e., without formula. The explanation made by Stu 1 allowed his classmates to better understand the problem and to give more meaning to the word "filtration of the medication". The previous event, supported by the explicit arguments given by Stu1, allowed several of his classmates to accept the solution, since they mentioned that he was right and that the procedure was coherent, since it considered the filtration, and complied with the cases taken by each one of them.

The above reasoning is shown in diagram in Figure 7.

From the previous schemes, we can see how Stu1's need to explain the answer to the teacher and to his 


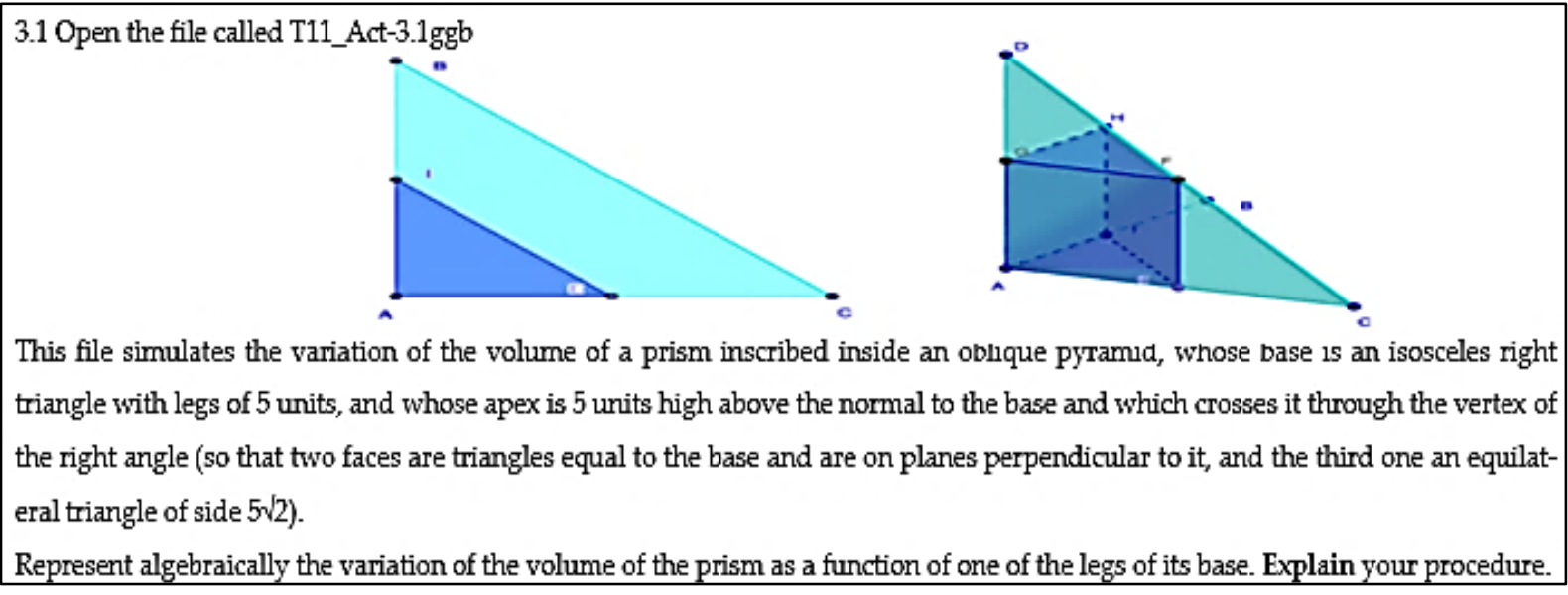

Figure 8. Variation problem proposed to students

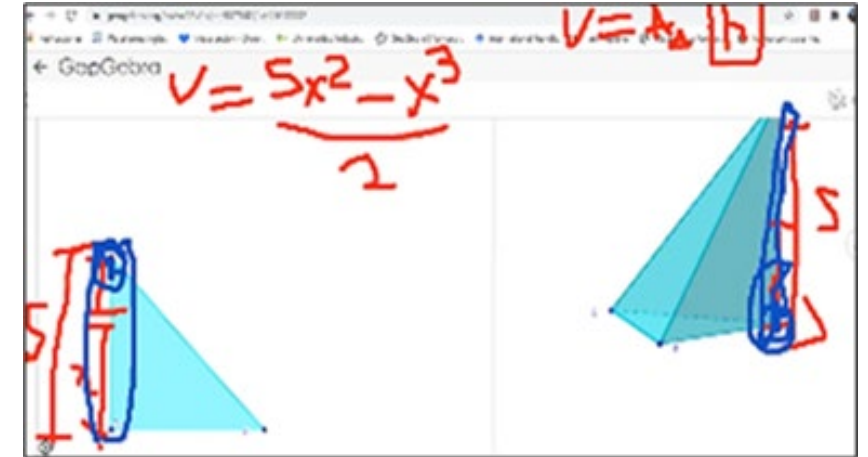

Figure 9. Screenshot of the problem interpretation

classmates makes the student himself identify the error in his answer (Re, Figure 5). In addition, with the interventions of the other members of the group, the opportunity is given for rethinking the conjecture.

Having clarity about the data referring to the behavior of the medications in the different intakes done every 8 hours, the student is oriented to continue with the iterative procedure until a generality is found. In the teacher's and students' interventions, rebuttals were evidenced ( $\operatorname{Re}_{1}$ and $\operatorname{Re}_{2}$, Figure 7 ), which led the student to change his conjecture. This allows him to rethink the procedure performed and conclude $C_{1}$ from theoretical rules, where the representation system composed by the numerical representation, the gestural and verbal language, and the algebraic language to represent the formula are evidenced. However, the control of the operators and of the process is carried out by the results of the calculator and the proof of the formula in the first values, which cannot be considered as a formal deductive demonstration, even though it is a good explanation of the solution of the problem.

\section{Justification Skill}

This skill is evidenced when students support, argue and explain whether a mathematical statement is true or false, and when answering whys of the process performed and conjectures made. This implies that the student convinces the teacher and his/her peers that the proposed reasoning is feasible to solve the problem; therefore, it is required to use propositions, mathematical properties, counter examples, reasoning and solid arguments that contribute to the veracity or refutation of the statements. An example of this skill is presented in Figure 8. 9).

Stu3: In answer a), the formula is $v=\frac{5 x^{2}-x^{3}}{2}$ (Figure

T: How did you get that result? (Figure 9).

Stu3: First I realized that some right triangles are formed, so I am going to express that by the legs and relate it to the volume.

Stu3: We know that the volume in this case is the area of the base times the height. So first we have to know which is this side (points to the left side) and the problem tells us that the big one is 5 and tells us that this one here (points to the right side) is also 5. So, to find the value of this one (points to the height of the inscribed prism) let's call it $x$ and here (points to the 3D Figure), to find the side that would be the height.

If we see, they are related these sides (left over $2 D$ Figure and highlighted in dark blue 3D Figure) are equal. (This, it does from the observed movement).

Stu2: Wait, how so? It would not be with the other part (what is in light color).

Stu3: No, look; I don't know how to explain it. You see, when you move the slider, this distance (shown in the $2 D$ Figure) is equal to this distance (points to the $3 D$ Figure), what is varying in this part (points to the dark blue color) are equal, because if we put it in two dimensions, here it would be zero and here too, the same with any other height that is parallel; for example, if you put all the height on the floor, it would be the same height of the prism.

Stu3: So, I find that relationship between those two sides. So, the height would be $h=5-x$ we already have a value to put it as a function of the other side.

Stu2: But wait because $h=5-x$ How so? 


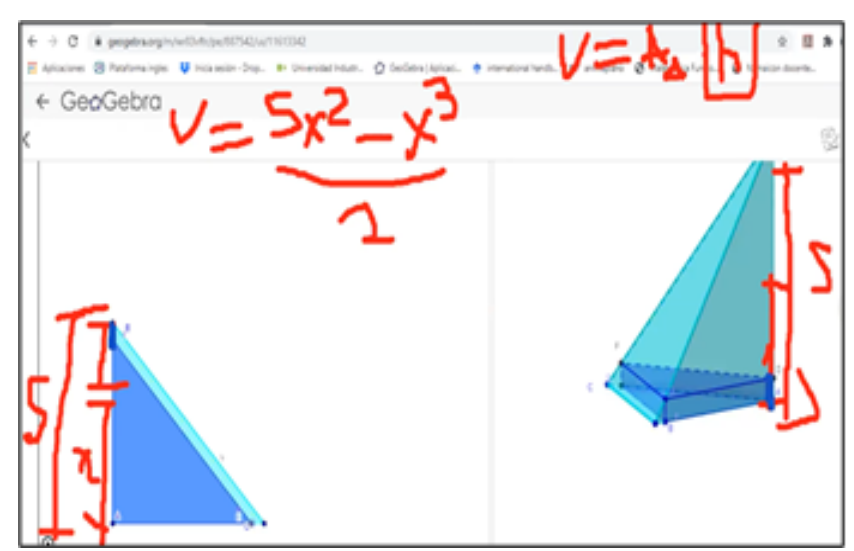

Figure 10. Screenshots Zoom Screen Share

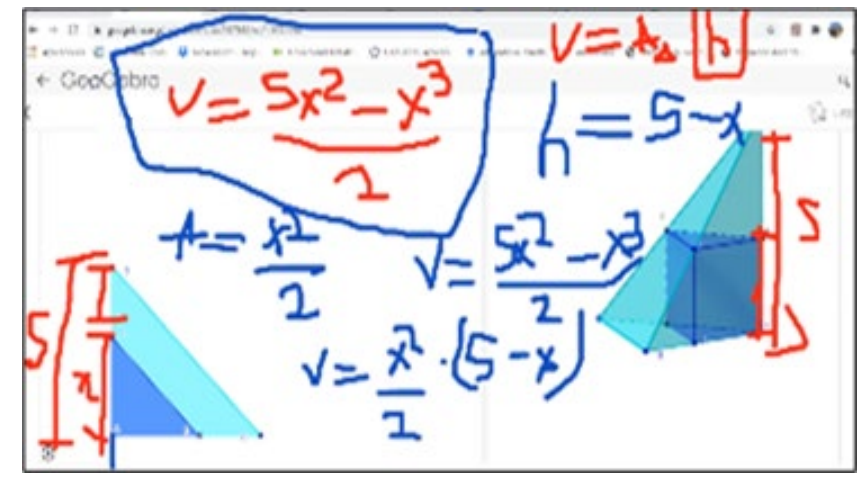

Figure 11. Screenshot of the solution of the problem

Stu3: Because of what I have just explained. (Argue again using what was exposed and written on Zoom Screen Share (Figure 10).

Stu3: Going back; then, we need the area of the base triangle. The area is equal to the base times the height times two. They are telling us that it is an isosceles triangle, so the height and the base are the same, we have: $A=\boldsymbol{b} \times \boldsymbol{h}=\frac{x^{2}}{2}$ so we just replace, everything is already a function of $x$ (Figure 11).

Thus, $v=\frac{x^{2}}{2}(5-x)=\frac{5 x^{2}-x^{3}}{2}$

Stu 1: Teacher, I also got to the same answer, I also did it this way.

Stu4: But that would not be $-x^{3}$, it would be $(5-x)^{3}$

Stu3: No, there we must do the multiplication term by term, that is, $x^{2}(5)$ and $x^{2}(-x)$.

Stu4: Umm... right, yes, I was wrong, sorry.

That can be seen in the Figure 12.

The answer given by Stu 3 shows the appropriate interpretation of the statement, which allows identifying the dependent and independent variables properly; also recognize the importance of expressing one variable as a function of the other. This leads to determine the data (D1, D2, D3, D4) that were the basis for the solution of the problem.

Through dialogue, it is evident that the student uses different representations of the same mathematical object of study (numerical, gestural, natural language,

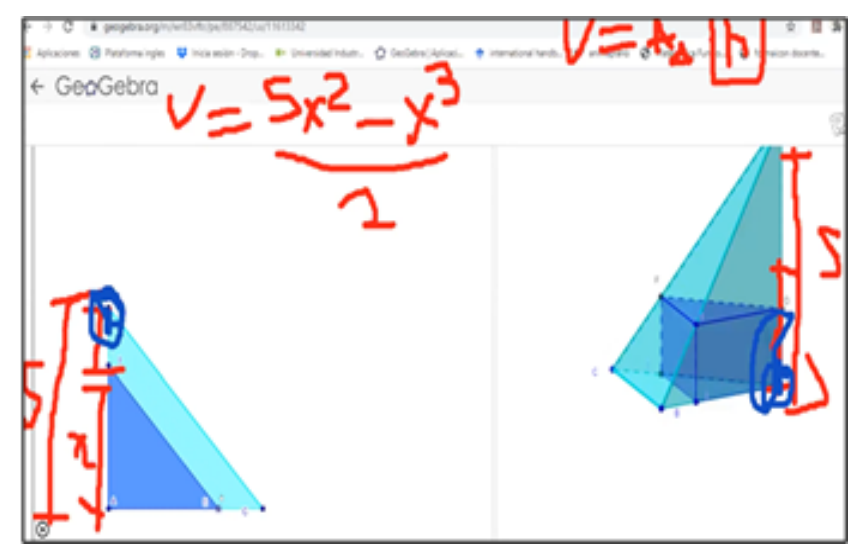

algebraic) that allow him to: identify mathematical properties, use theoretical rules, reasoning and mathematical arguments to justify that his conjecture $\left(V=\frac{5 x^{2}-x^{3}}{2}\right)$ is appropriate.

From Re1 the student is oriented to the importance of justifying his answer and the procedure carried out, for this, the arguments given from R1 to R4 become a key piece, since they show that the student uses theoretical arguments such as the volume of a prism, area of a triangle, knowledge about the right triangle, which allow him to give a clear and concise solution to the problem, which is evidenced in C1.

\section{Argumentation Skill}

The argumentation skill is present in students when they want to convince themselves, peers or teachers that the actions performed contribute to the veracity of the conjecture. For this, explanations and justifications must be given by means of symbolic notations, representations, mathematical properties, verbal, graphic or written language, which allow understanding the idea to be transmitted. By means of activity $\mathrm{N}^{\circ} 1$ of workshop 12 (Figure 13), it is intended to account for the argumentation skills acquired by the students in the precalculus laboratory course.

Some students continue using the strategy of using particular cases to find the maximum area (inductive reasoning), they also use different representations, such as: graphing, tabular or numerical representation of the same mathematical object to conjecture about the relevant dimensions to find the rectangle with the largest area. Other students, from the beginning when taking particular cases, evidenced that the dimensions of the quadrilateral of the greater area is a square, however, not considering that a square can be a rectangle, they discarded this solution. It is worth noting that the students try to use a more solid mathematical language, however, they start from data that the problem does not provide, such as assuming that the base of the rectangle is twice the height and considering it as a square (Figure 14). 


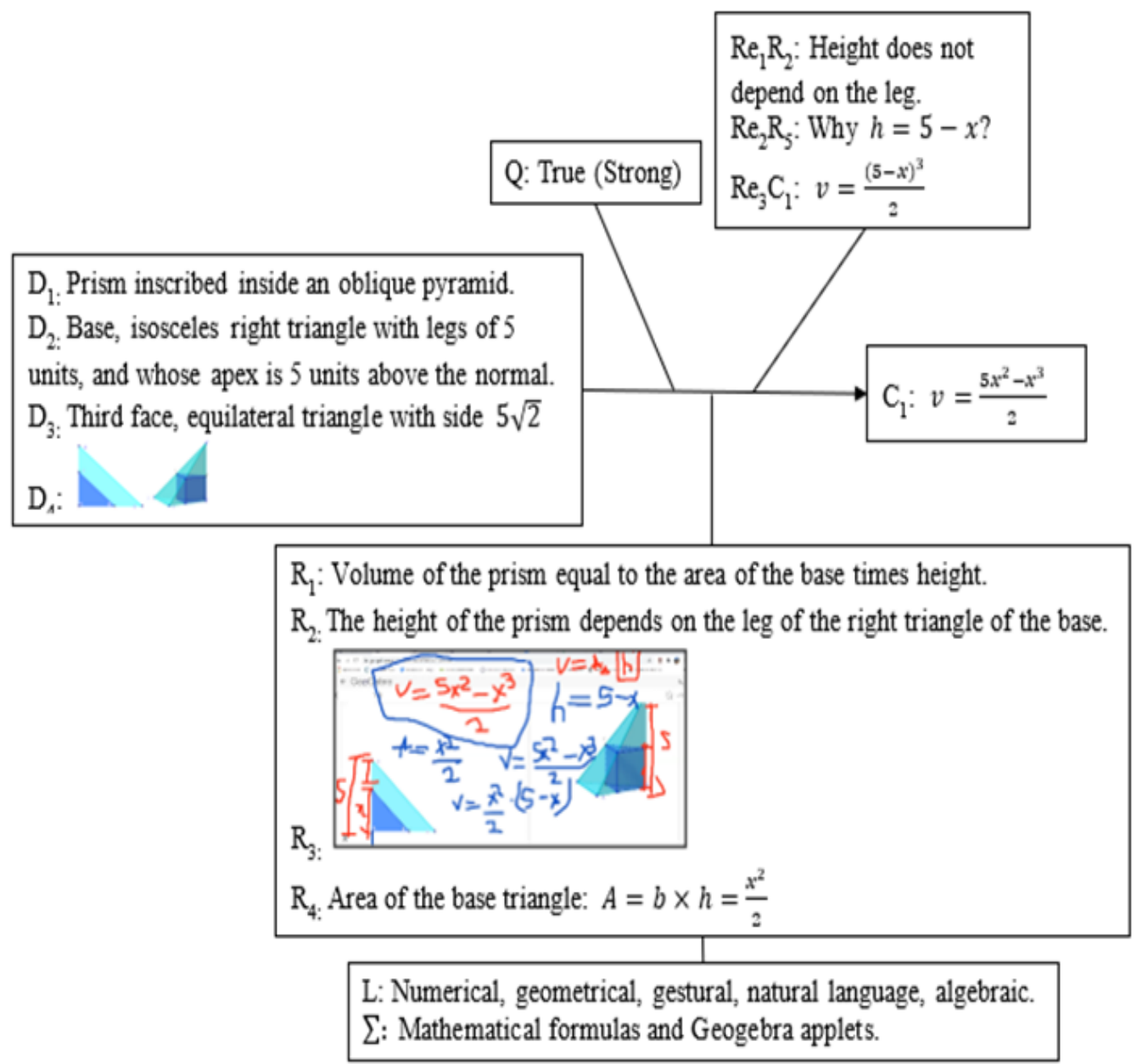

Figure 12. Scheme of the process of justification of the given problem (acknowledge theorist)

Activity 12.1
The perimeter of a rectangle is 14 meters. Find the dimensions of this quadrilateral so that its area is the
maximum possible. Explain and justify your answer on the worksheet.
$\frac{\boldsymbol{A}}{f_{\mathbf{x}}}$

Figure 13. Variation and change problem, activity 12.1, workshop 12

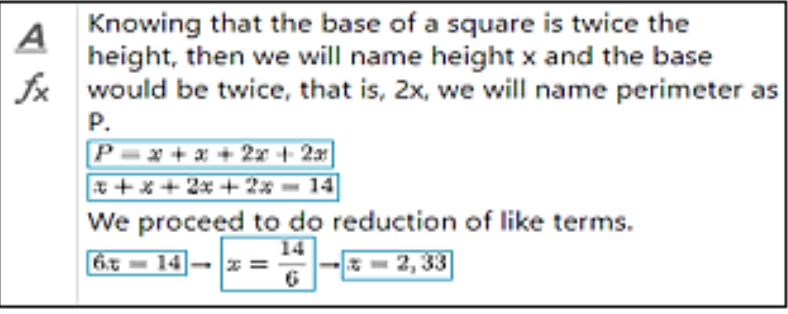

Figure 14. Interpretation of the problem by a student

Faced with the process carried out by the student, many of his classmates disagreed, and invalidated the result, showing other values for the base and height of the rectangle that gave a larger area. Below, we present a small dialogue in which we show the previously mentioned.

\begin{tabular}{|l}
$\underline{A} \begin{array}{l}\text { Knowing the value of } 2,33 x \\
\text { base is double, it would be } 2 \pi=4,66\end{array}$ \\
$f_{x} \quad \begin{array}{l}\text { Knowing all the data only remains to } \\
\text { find the area which is: } \\
a=x h \rightarrow a=4,66(2,33)\end{array} \rightarrow a=10,87$
\end{tabular}

Stu5: I think my classmate did something wrong, because he takes it as if they are asking for a square in the solution. Just like that, he describes it by saying "knowing that the base of a square is twice the height" and the problem asks for a rectangle. Also, at no point does my classmate mention and (height). He also takes 


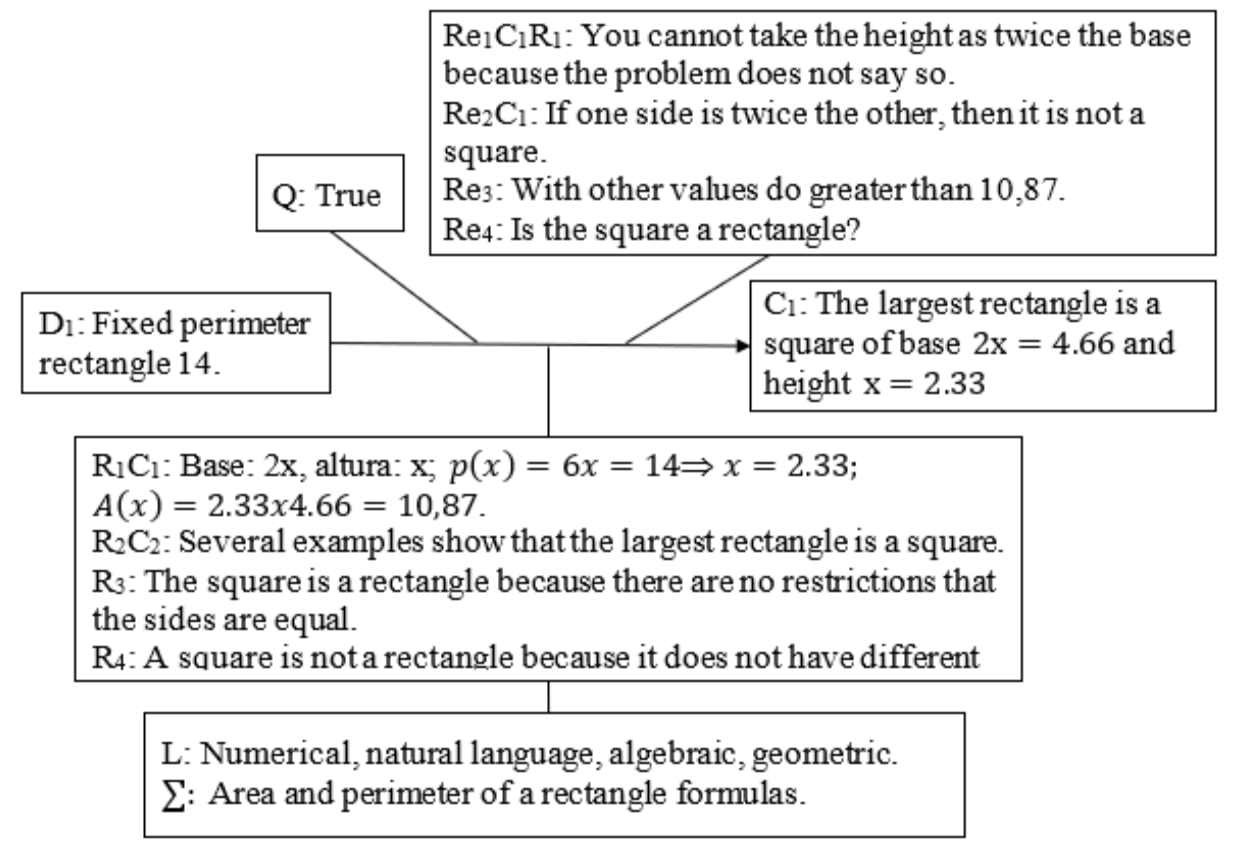

Figure 15. Scheme, argumentation process diagram

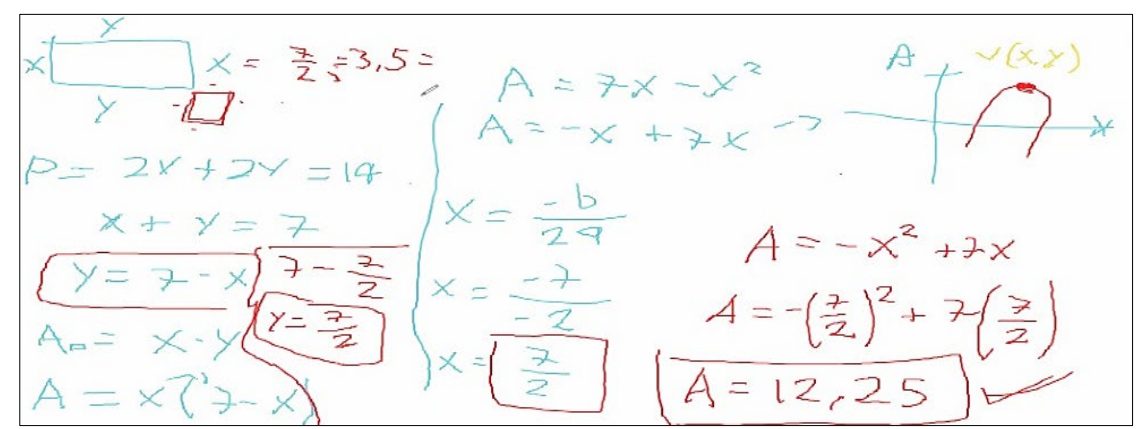

Figure 16. Mathematical solution to activity 12.1 of workshop 12

that all sides are equal and let's remember that in the rectangle there are two unequal sides. Also, he is taking one of the sides as twice the other and we don't know that the problem only gives us the perimeter.

Stu2: Teacher, that is a hypothesis he has, but why the double? The problem doesn't say. Besides, if one side is double the other it could not be a square as he mentions.

Stu4: Teacher, but that hypothesis is not correct, because I found other values where the area is greater, the values that I took 4 and 3 , because we know that the area of a rectangle is base times height, then, it doesn't matter which of these magnitudes is the base or the height, because the result as area is the same, it is 12 and these magnitudes satisfy that $P=14=4+4+3+3$.

From these conjectures and possible solutions, the following dialogue emerged:

$\mathbf{T}$ : What is a rectangle, what is a square, is a square a rectangle, is a rectangle a square?

Stu2: A square is a rectangle, but a rectangle is not always a square, because a rectangle is a four-sided, closed figure that has its sides parallel two by two, there is no restriction that says that in a rectangle two sides are unequal.

Stu6: A square is not a rectangle, although the rectangle and the square are quadrilaterals because they have four sides, but in the square all its sides are equal, while in the rectangle it has different bases and heights.

Stu2: No teacher, I don't agree with them. I am still convinced that a square can be a rectangle, because in the definition of rectangle there is no restriction that they have to be unequal.

It is proposed to the students to reflect on this concern, which will later be taken up for the solution of the problem.

In Figure 15 we present the interpretation derived from the student's solution.

Resuming the problem, a group of students mentions that they obtained the same result as other classmates (solution a square), but that they did not do it using particular cases, rather they used a more generalized approach by assigning variables to the sides and clearing one variable as a function of the other, as evidenced in Figure 16 (students mention: teacher, there are two 

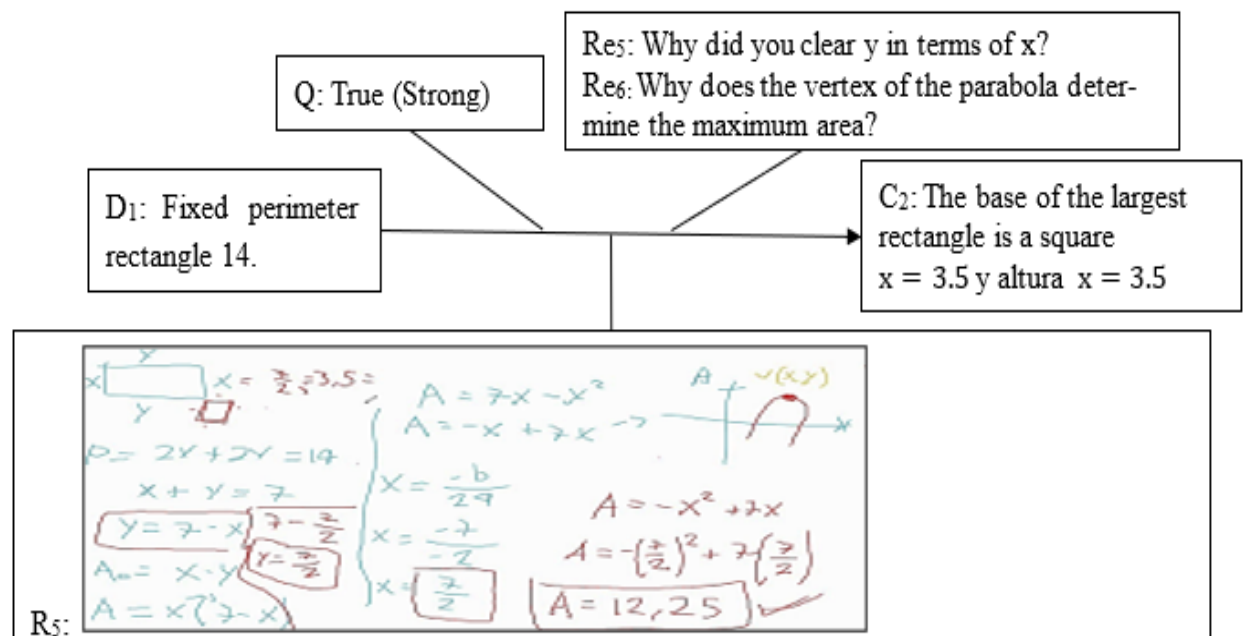

$\mathrm{R}_{6}$ : It is necessary to put everything in function of a single variable.

$\mathrm{R}_{7}$ : The function represents a parabola that opens downward, then you have the maximum.

$\mathrm{R}_{8}$ : The maximum area is found when we know the vertex of this parabola.

$\mathrm{R}$ : The vertex of the parabola is at $x=-\frac{b}{2 a}$

L: Numerical, natural language, algebraic, geometric, analytical.

$\sum$ : Area and perimeter of a rectangle formulas and the vertex of a parabola, definition of rectangle and square, interdependence between variables, coordination between geometric, algebraic, graphic and numerical representations.

Figure 17. Scheme of the argumentation process evidenced in the resolution of the problem

solutions because it was worked in group section, but converge to the same thing would be to choose one).

The explanation and justification of the students were the following: "to find the perimeter of a rectangle we use the formulas we already know, then we have that $p=2 x+2 y=14$ where $y$ the base of the rectangle and $x$ its height. From this equation, we clear $y$ as a function of $x$ and we have that $y=\frac{14-2 X}{2}=7-x$, so the base is $y=7-x^{\prime \prime}$

T: Why did you clear $y$ in terms of $x$ ?

Stu1: To put all variables as a function of one variable, because then we can get the value of one side and find the area.

Stu2: Teacher, besides, if we have everything in function of one variable, we could solve the problem easier, because in function of two variables it is very complex.

Stu1: then we replace the variable $y$ in the formula to find the area of the rectangle, which is $A=(x)(y)$ then, we have $A=(x)(7-x)=7 x-x^{2}=-x^{2}+7 x$.

The previous function represents a parabola that opens downward, then the maximum area is found when we know the vertex of this parabola. Then, to find the vertex of the parabola we have that $x=-\frac{b}{2 a}$ knowing that $\mathrm{b}=7$ and $\mathrm{a}=-1$ we can deduce that $x=\frac{-7}{2(-1)}$. Now replacing $x$ in the function found, we have that $A=$ $-\left(\frac{7}{2}\right)^{2}+7\left(\frac{7}{2}\right)=12,25$
T: Why does the vertex of the parabola determine the maximum area?

Stu6: Teacher, because the function is a parabola with a negative sign, that is, it opens downward so we have a maximum. If it opened upwards, we would have a minimum.

T: So, what are the dimensions of the rectangle that are asked for?

Stu3: Well, as we have already $x$ we know that $y=$ $7-x=7-\frac{7}{2}=\frac{7}{2}$. Then, $x=y=\frac{7}{2}$ that is a square.

From the above, one of the students stated that the solution to the problem was a square, so a square could be a rectangle, because it was the one that was the largest area as we have already demonstrated, a situation that we present in Figure 17.

From what was previously demostrated and from the schemes taught, the richness of the discussions that invite all the students in the group to expose and defend their ideas with a view to convincing the others, despite even the raising of erroneous conjectures, a fact that highlights the strength of strong inference and the potential refutations that validate or invalidate the operators of the conception, stands out, accounting, in this case, of abductive reasoning. Although a demonstration was not requested, in Margolinas terms, the procedure performed by the group of students also shows the validation skill that we will analyze in the next section, since the students are concerned with trying to know if the result obtained suits the problem posed 
Activity 11.1

Take a rectangular letter-size sheet of paper and, without trimming, make a cylinder without lids.

Considering each of the largest and smallest sides of the rectangle as the possible height of the cylinder, how do you obtain the largest volume of the solid? With the largest or the smallest of the sides? Justify your choice.

a) What can be conjectured from any rectangular sheet? Explain your answer.

b) What can be conjectured from any square sheet? Explain your answer.

c) Compare your results with a partner, and show him/her that your conjectures are true.

$\underline{A}$

$f_{x}$

Figure 18. Variation and change problem, activity 11.1 of workshop 11

(Margolinas, 2009, p. 22), by analyzing the answer and checking with different values.

\section{Validation Skill}

Validation requires the student to give reasons, to justify his assertions and must be willing to defend them with the intention of convincing the peer group. Validation brings into play mutual sharing where the decisions taken are debated and the need to guarantee their validity or to denounce that one does not agree with the arguments of the other is manifested. Validation is characterized by the desire to give strength or firmness to what has been concluded, to make it valid. To demonstrate the above, we present the solution of some students to the activity No 11.1 of workshop 11, (Figure 18).

From the solutions given by the students it is observed that, in the first instance, they tend to solve the problem by assigning particular measures to the sheet. From this, they conjecture that the larger volume is obtained by using the smallest side of the sheet as the height, except when the sheet is square, since the volumes are equal.

The particular examples allow students to make some conjectures, however, for them, this process was no longer sufficient, since they had acquired the ability to question themselves about the reason for the statements, in addition to the need to clearly argue that the conjecture was true for all values taken and not only for some specific cases, therefore, they try through more convincing theoretical arguments and mathematical properties to demonstrate the proposed conjecture. This means that the intervention begins to come to fruition, as a result of a systematic work from the implementation of the first activity, which involves the design and methodology of the course, together with the guidance of the teacher, promoting conjectures and the need to argue and validate with theoretical elements. This situation is evidenced by the following dialogue:

Stu3: The same volume is obtained, since having equal sides in my square sheet gives the same result.
Stu2: That is not true, teacher, the problem does not say that it is a square sheet.

Stu3: I give this answer because in the exercise it tells us to take a sheet of paper, and a sheet of paper will always have the same measurements, so I do not understand why my answer cannot be valid?

It is necessary to emphasize that this answer given by the student corresponds to item a, since the student started from a sheet with equal size.

Stu2: because if we take a letter-size sheet of paper, it does not have the same horizontal and vertical sizes, if it were a square that has the same sizes on any side, then it does satisfy your conjecture.

Stu7: I agree with my peer. Not all sheets are square, for example, if we take a legal sheet, it is clear that they are not the same dimensions.

Stu3: Sure, I only took into account the square sheet, so, teacher, when you have a square sheet, it doesn't matter how you take it, right? the volume is the same.

T: Exactly. Now, what happens if you don't have a square sheet?

Students: Teacher, with the exercises we did, the largest volume is when the smallest side of the sheet is taken as the height.

T: How could we prove that to be true for any sheet of paper taken?

Stu7: We could do this by comparing the volume of the cylinder formula and the perimeter of the circle.

T: How?

Stu7: let's say that the sheet is like this (Figure 19 on the left) on the shortest side I put a value of 5 and on the longest side I put a value of 10 . Then we make the corresponding cylinder with a height of five and on the other side we make the other cylinder, but with a height of 10 (Figure 19 on the right).

Now, to obtain the radius we put that the perimeter of the first cylinder is equal to 10 , i.e., $P=2 \pi r=10$ and to obtain the radius we clear, and we get that $r=\frac{10}{2 \pi}$ simplifying we get $r=\frac{5}{\pi}$ as we already have the radius, 


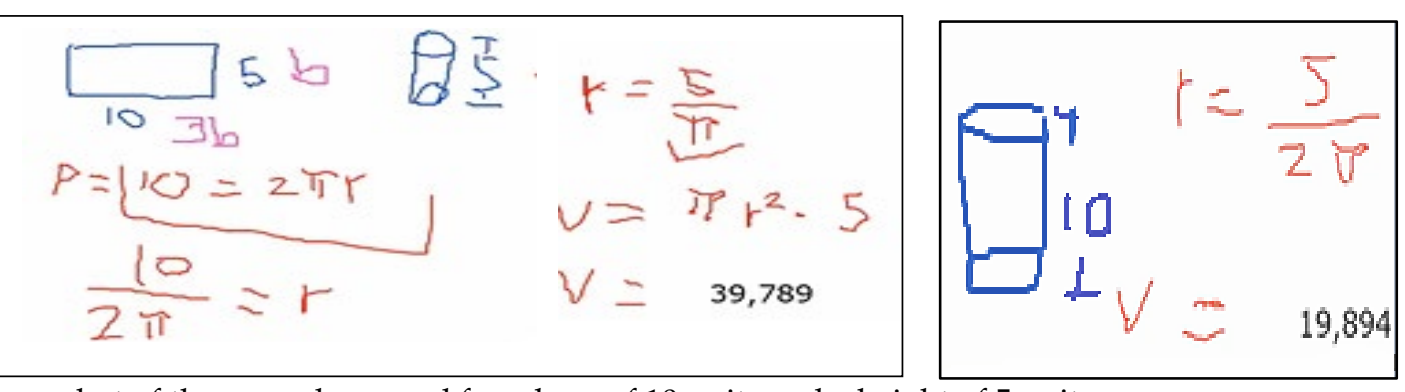

Figure 19. Screenshot of the procedure used for a base of 10 units and a height of 5 units

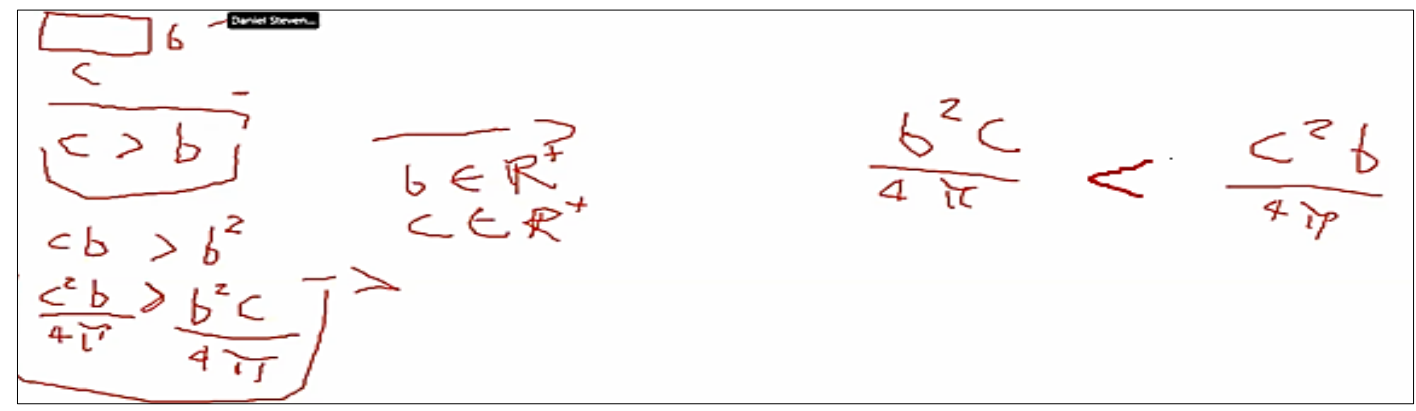

Figure 20. Problem solving screenshot for a sheet of any dimension

we can find the volume of that cylinder, using the formula $V=\pi r^{2} h$ replacing it we have $V=\pi\left(\frac{5}{\pi}\right)^{2} 5=$ 39,789 (Figure 19). Doing the same procedure with the other cylinder with opposite dimensions we have that $r=\frac{5}{2 \pi}$ and replacing $\mathrm{r}$ in the formula of the volume we get $V=\pi\left(\frac{5}{2 \pi}\right)^{2} 10=19,894$ (Figure 19) That's all, so we could show it and if we want to generalize it would be to replace the dimensions 5 and 10 by any variable. So, we can see that when we take the shortest distance from the height of the cylinder, it gives us a considerably larger volume. This will always be true.

Stu8: How do you know that it will always hold? Well, in that particular case it is fulfilling. But we already know that it is not enough that it fulfills for that one, we must see it in a general way, that is, for any sheet of paper that I take and of any dimension.

Stu9: Applying what my classmate just did with other values will give us that it is true and that our conjecture is true for any value we take with that condition.

T: How do we generalize and say that for everything it holds?

Stu1: Teacher, teacher, let's assign general variables (Figure 20) let's say $c>b$.

If the circular base is formed with side $c$, and we follow the previous procedure, we have that $V 1=\frac{b c^{2}}{4 \pi}$ and if we form the circular base with $b$ we have $V 2=\frac{c b^{2}}{4 \pi}$.

If we assume that $c>b$ we can get the above because by multiplying both sides by $b>0$ and $c>0$, there is left $c^{2} \mathrm{~b}>b^{2} c$ and dividing by $4 \pi$ on both sides we have that: $V 1=\frac{b c^{2}}{4 \pi}>V 2=\frac{c b^{2}}{4 \pi}$.
Thus, from the students' interactions and examples given through particular cases, they themselves manage to generalize why $c$ and $b$ can take any positive value. This allows them to demonstrate the conjecture they had raised, by applying the properties and solving the respective operations (Figure 20).

Students: Well, teacher, what my partner says is true, and it is coherent with the particular examples we gave, that if would be the demonstration for any value we give to the variables $b$ and $c$, besides, it is using mathematical properties that makes it always works.

The previous dialogue and Figure 21 show that the students, starting from articular cases, managed to realize the error of statement 1 and demonstrate statement 2 , because following the process they see there immersed some properties of the real numbers that allow them to operate easily, which is achieved in turn before the rebuttals $\operatorname{Re}_{1}$ to $\operatorname{Re}_{4}$.

Likewise, since some students were not convinced of the processes carried out term by term, they requested that the conjecture be proved for a sheet of any dimension. This led them to think about the problem in terms of the use of variables, conditions and properties of real numbers, which finally helped them to identify the radius as a function of the length of its sides, subsequently replacing it in the volume equation and thus get the expected result. This episode explains the shift from a form of inductive reasoning to a form of deductive reasoning, which is essential for the construction of mathematical proofs.

It should be noted that the different representations (numerical, geometric, algebraic, the use of natural and symbolic language) of the same mathematical object of study allowed students to generalize and establish some 


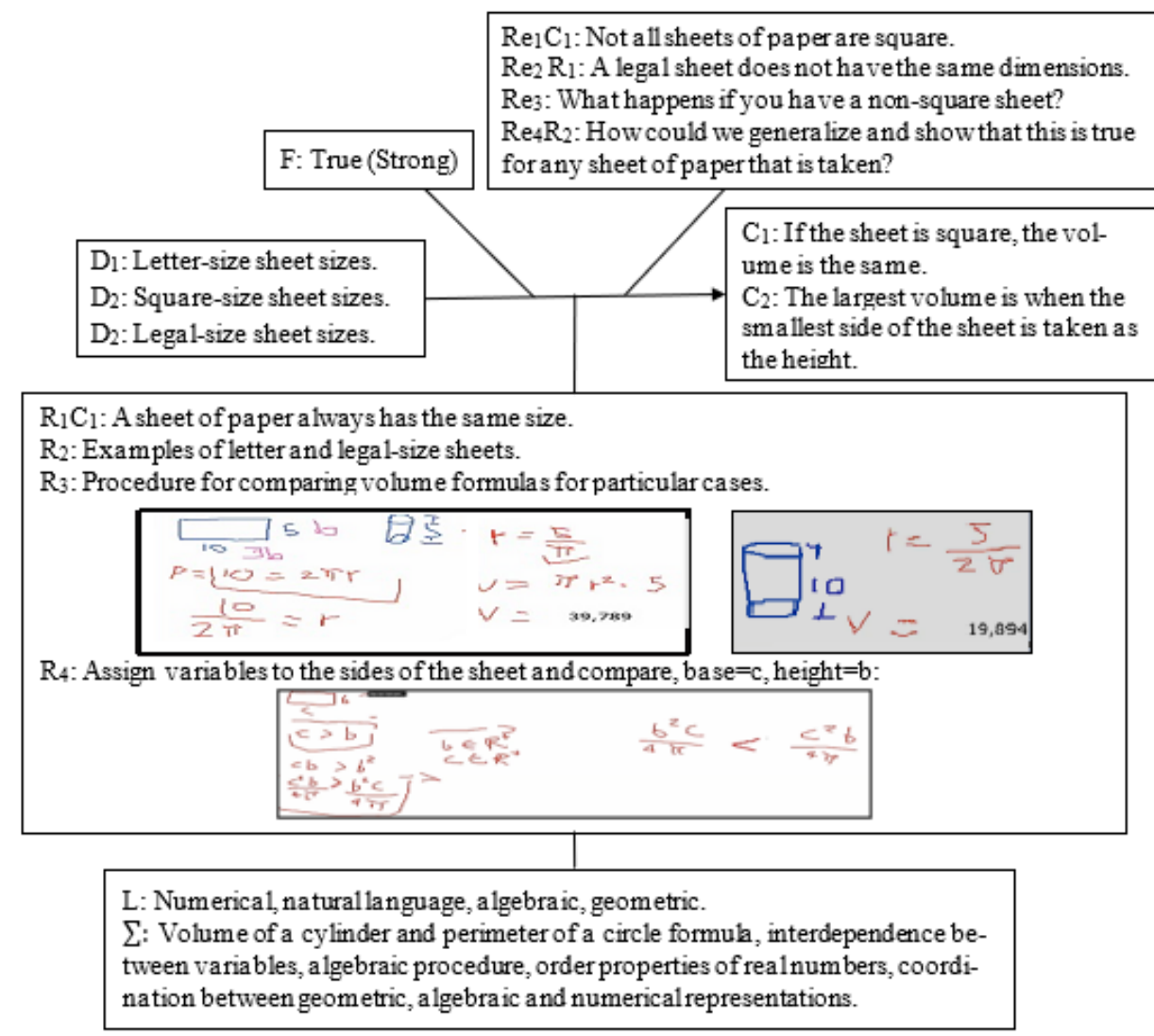

Figure 21. Scheme of the Toulmin model (date) for the validation process

conjectures, which allowed them to understand and solve the problem, as well as to realize these through the expressions and procedures carried out for the comparison of the volumes and thus convince the group of the veracity of the conjecture raised. This conviction is also manifested in the ability to successfully and functionally integrate or merge explanation, justification, argumentation and validation.

Theoretical control supported by the formulas of volume of a cylinder and perimeter of a circumference, algebraic procedures and order properties of real numbers, is also evident, which allows them to construct a deductive demonstration, like a mental experiment. (Fiallo, 2011), based on the use of examples to remember mathematical properties and procedures, which he then uses as theoretical arguments $\left(\mathrm{R}_{3}\right)$, without the need to return to the examples.

\section{CONCLUSIONS}

In this session we will present the emerging conclusions of the classroom intervention, for which we characterize the demonstration skills, based on the elements that make up Toulmin's schemas, Pedemonte's analysis model and the results evidenced in the different versions that the classroom intervention has been carried.

\section{Explanation Skill}

Explanation skill is characterized by the fact that the warrant is weak, there is no total conviction of the explaining learner, nor does he/she feel the need to convince others, which makes rebuttals not so relevant. The operators of the conception are usually examples of numerical calculations or of checking some properties in particular cases, the representation system is mainly composed of numerical or geometrical representations (according to the Douady (1986) framework of the problem), and there is a scarce use of the algebraic representation system; explanations are usually given in natural and gestural language. Because of this representation system, the control structure is based on checking, visualizing or calculating the results on the calculator or in the GeoGebra applet, as sufficient proof of the validity of the operators. Using Toulmin's scheme, we propose the scheme in Figure 22 to characterize the explanation skill.

In this skill we evidenced that when students did not understand the problem correctly, the explanation given to the solution of the problem was without solid arguments, and they did not have a logical construct of the ideas that allowed them to account for the veracity of their conjectures, which were giving new meaning through collaborative work and discussion between students and teacher that led to the construction of mathematical concepts, use of mathematical language, 


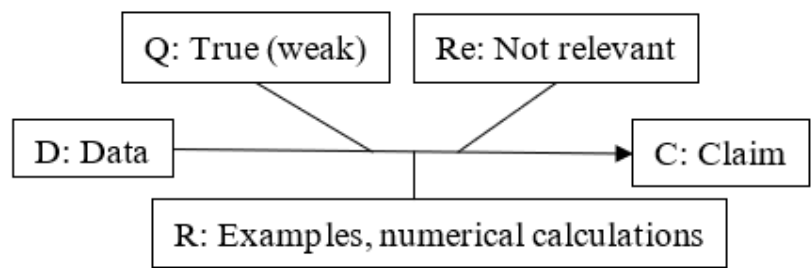

L: Numeric, gestures, natural language.

$\sum$ : Result of operations, calculator, GeoGebra applets for validation

Figure 22. Scheme of the Toulmin model (date) for explanation skill

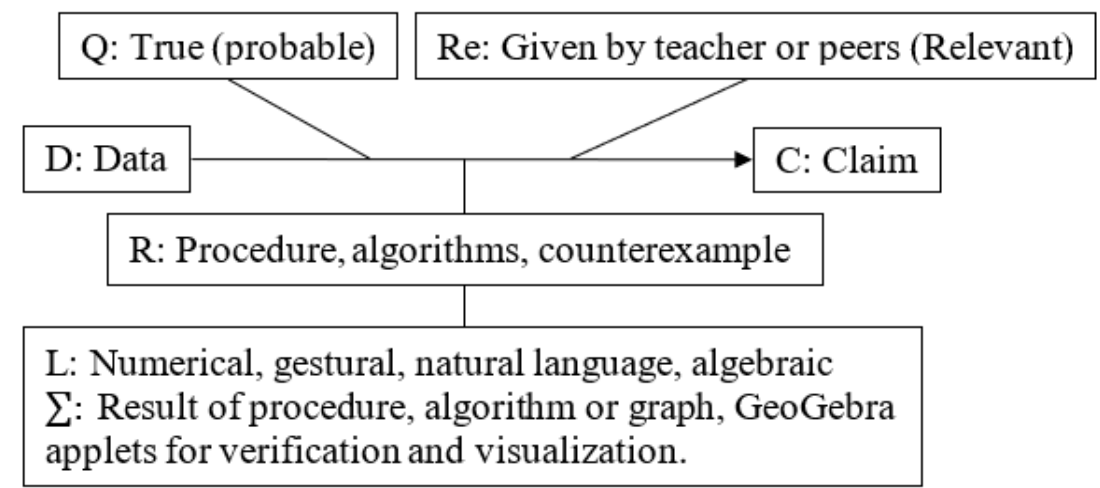

Figure 23. Scheme of Toulmin's model (date) for justification skill

given the interest that the other peer understood what was being explained.

\section{Justification Skill}

In justification, the qualifier has a greater probability of certainty due to the need to give reasons for the conjecture (Jorba, Gómez y Prat, 1998; Rigo, Rojano \& Pluvinage, 2011), which leads to the use of operators, generally based on procedures, algorithms and counterexamples, because rebuttals become relevant in this skill. In the representation system there is a greater use of the algebraic representation system and there is evidence of a first attempt at coordination Duval (2004) between the different representation systems, use is made of graphics in the Cartesian plane and the control structure of the operators is based on the results of procedures, algorithms, formulas and graphics. There is a more controlled use of GeoGebra applets by students to verify their arguments.

Using Toulmin's scheme, we propose the following scheme (Figure 23) to characterize the justification skill. This was one of the skills that was developed to a greater extent, through the moments of sharing answers and concerns, since when the students provided an answer and their classmates disagreed, they were referred to ask about the why of the statements made. This situation led them to rethink their justifications and relate the different representations (graphical, numerical, algebraic) of a mathematical object that allowed them to show the variation between two variables, dependence and independence, compare data from a table with those obtained in an algebraic expression, among others.

\section{Argumentation Skill}

The argumentation skill is characterized by the degree to which the speaker is convinced of the veracity of his conjecture (even if it is false) and the desire to convince others (Pedemonte, 2002), so that rebuttals become more relevant.

In accordance with the above, due to the high degree of discussion generated by promoting the argumentation skill, all members of the group were attentive and asked questions questioning the operators of the conception, characterized by the use of theoretical rules and mathematical properties and a coordination Duval (2004) between different representation systems, including executable representations, and a theoretical control structure based on adequate and accepted mathematical procedures and properties.

There is a controlled use of GeoGebra applets by students to test conjectures, ideas, explore and find properties. Using Toulmin's scheme, we propose the scheme in Figure 24 to characterize the argumentation skill.

We evidenced a significant progress in the argumentation and justification by the students in solving problems of variation and change, since it was no longer enough for them to take some particular cases that showed the veracity of the conjectures and algebraic expressions found, but they were concerned about 


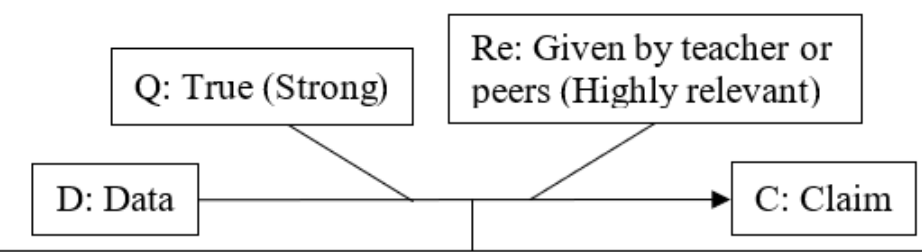

$\mathrm{R}$ : Theoretical rules, mathematical procedures and properties

L: Coordination between representation systems (numerical, gestural, natural language, algebraic, graphic, analytical).

$\sum::$ Theoretical, GeoGebra applets for testing, exploring and finding mathematical properties.

Figure 24. Scheme of Toulmin's model (date) for argumentation skill

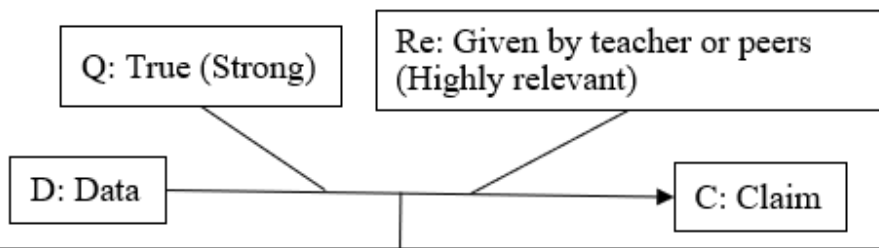

$\mathrm{R}$ : Theoretical rules, mathematical procedures and properties

L: Coordination between representation systems (numerical, gestural, natural language, algebraic, graphic, analytical).

$\sum$ : Theoretical, definitions, axioms, theorems, GeoGebra applets for testing, exploring and verifying mathematical properties.

Figure 25. Scheme of the Toulmin model for the validation skill

arguing from the theory the proposed results, as evidenced in the previously mentioned situations. Likewise, the use of a more adequate mathematical language to refer to the objects involved in the problem (variables, equations, functions, among others) is perceived.

\section{Validation Skill}

In the validation skill, in addition to what is exposed in the other skills, which could be considered as ascending levels, the outstanding element of Toulmin's scheme is the Backing (B), characterized by the ability to coordinate all the representation systems necessary for the solution of the problem and a control structure based on definitions, axioms, theorems and appropriate mathematical procedures. The use of GeoGebra applets makes it possible to visualize, understand, validate and coordinate the different representation systems of the software to guarantee the validity of the arguments.

Taking into account Margolinas's (2009) viewpoint, although validation should not necessarily be linked to demonstration, we argue that giving an answer to a problem, even with an adequate mathematical procedure, could be considered a demonstration in the framework of calculus, since the operators of the conception and the theoretical and procedural support give veracity and validity to the conjectures raised and ensure the degree of conviction of all members of the group. Using Toulmin's scheme, we propose the following scheme (Figure 25) to characterize the validation skill.

The analysis of the four skills consolidated in the four schemes is taken as a proposal, a product of this research based on a classroom intervention of several years. It is suggested that in order to understand and be able to perform mathematical demonstrations of the most important theorems of calculus, it is necessary to promote these skills, recognizing in them a hierarchical order that progresses from explanation to validation.

The analysis of the four problems presented above shows the development of the demonstration skill through problems of variation and change, since through the explanation, justification, argumentation and validation skills, students move between particular examples to generalize and subsequently demonstrate mathematically that the conjecture presented is true.

\section{FINAL REFLECTIONS}

The experimentation with the precalculus course, the context of the study from which this article is extracted, has been developed over nine years with twelve cohorts of undergraduate students of science and engineering. 
Such experimentation, has allowed us to build theoretical and practical knowledge, from which different research products have emerged that are summarized in Fiallo \& Parada (2018). For mathematics educators who want to follow this path of reflection and research, from other areas of mathematics, it is suggested to critically analyze the purposes of learning and privilege mathematical processes rather than objects of study, problematizing around interesting and useful situations for students.

On the other hand, although we consider that the skills of the demonstration process identified through the precalculus laboratory course could be evidenced in other courses, we must be honest in saying that we have not done research from other fields of mathematics. However, we admit that there is a very fertile field to explore and that we have the obligation to venture into them, in order to contribute to the mathematical education of the new generations.

Author contributions: All authors have sufficiently contributed to the study, and agreed with the results and conclusions.

Funding: We thank the Vice Rector's Office for Research and Extension, and the Academic Vice Rector's Office of the Universidad Industrial de Santander for having financed the research project 2425,2679 and the pre-calculus course during the last 8 years, respectively.

Declaration of interest: No conflict of interest is declared by authors.

\section{REFERENCES}

Balacheff, N. (1995). Conception, connaissance et concept [Design, knowledge and concept]. In D. Grenier (Ed.), Didactique et technologies cognitives en mathématiques, séminaires 1994-1995 (pp. 219-244). Université Joseph Fourier.

Balacheff, N. (2000). Entornos informáticos para la enseñanza de las matemáticas: complejidad didáctica y expectativas [Computer environments for teaching mathematics: didactic complexity and expectations]. In Matemáticas y educación: retos y cambios desde una perspectiva internacional (pp. 91108). Grao.

Balacheff, N., \& Margolinas, C. (2005). cKథ Modèle de connaissances pour le calcul de situations didactiques [cK\$ knowledge model for calculating didactic situations]. In A. Mercier, \& C. Margolinas (Eds.), Balises pour la didactique des mathématiques (pp. 75-106). La Pensée Sauvage -Editions.

Bautista, R. (2018). Desarrollo del proceso de comunicación en la enseñanza y el aprendizaje de la geometría en un entorno de geometría dinámica [Development of the communication process in the teaching and learning of geometry in a dynamic geometry environment] (Unpublished master's thesis). Universidad Industrial de Santander, Bucaramanga, Colombia.
Douady, R. (1986). Jeux de cadres et dialectique outilobjet [Framesets and tool-object dialectic]. Recherches en Didactique des Mathématiques, 7(2), 531.

Duval, R. (1992-1993). Argumenter, demontrer, expliquer: continuité ou rupture cognitive? [Argue, demonstrate, explain: continuity or cognitive rupture?] Petit $x, 31,37-61$.

Duval, R. (2004). Semiosis y pensamiento humano: registros semióticos y aprendizajes intelectuales [Semiosis and human thought: semiotic registers and intellectual learning]. Universidad del Valle.

Fiallo, J. (2011). Estudio del proceso de demostración en el aprendizaje de las razones trigonométricas en un ambiente de geometría dinámica [Study of the demonstration process in learning trigonometric ratios in a dynamic geometry environment] (Doctoral thesis). Universitat de València, España.

Fiallo, J., \& Parada, S. (2018). Estudio dinámico del cambio y la variación: curso de Precálculo mediado por GeoGebra [Dynamic study of change and variation: Precalculus course mediated by GeoGebra] (UIS Edition), Bucaramanga, Colombia.

González, V., \& Rodríguez, M. (2006). Un modelo para evaluar la validación matemática [A model to evaluate mathematical validation]. Educación Matemática, 18(3), 103-124.

Jorba, J., Gómez, I., \& Prat, A. (Eds.) (1998). Parlar i escriure per aprendre [Speak and write to learn]. ICE/UAB.

Margolinas, C. (2009). La importancia de lo verdadero y de lo falso en la clase de matemáticas [The importance of true and false in math class]. (M. Acosta, \& J. Fiallo, Trans.). Universidad Industrial de Santander.

Ministerio de Educación Nacional (MEN). (1998). Lineamientos curriculares para el área de matemáticas. Áreas obligatorias y fundamentales [Curricular guidelines for the area of mathematics. Mandatory and fundamental áreas].

Ministerio de Educación Nacional (MEN). (2006). Estándares Básicos de Matemáticas, 2006 [Basic Mathematics Standards, 2006].

Moreno, L. (2014). Educación Matemática: del signo al pixel. Editorial UIS [Mathematical Education: from the sign to the pixel. UIS Editorial]. Universidad Industrial de Santander, Colombia.

NCTM. (2003). Principios y estándares para la educación matemática [Principles and standards for mathematics education]. Sociedad Andaluza de Educación Matemática Thales. Colombia.

Neira, G. (2000). El paso del álgebra al cálculo: punto fundamental para lograr una comprensión significativa en matemáticas [The move from algebra to calculus: a fundamental point for 
achieving a meaningful understanding in mathematics]. Ingeniería, 5(1), 87-92.

Pedemonte, B. (2002). Etude didactique et cognitive des rapports de l'argumentation et de la démostration dans le apprentisage des mathématiques [Etude didactique et cognitive des rapports de l'argumentation et de la demonstration dans le apprentisage des mathématiques] (Doctoral thesis). Université Joseph Fourier - Grenoble I, Grenoble.

Pedemonte, B. (2005). Quelques outils pour l'analyse cognitive du rapport entre argumentation et démonstration [Quelques outils pour l'analyse cognitive $\mathrm{du}$ rapport entre argumentation et démonstration]. Recherches en didactique des mathematiques, 25(3), 313-348.

Polya, G. (1996). Matemáticas y razonamiento plausible [Mathematics and plausible reasoning]. Madrid, Spain.

Project 2425. (2018). Estudio de los procesos matemáticos que desarrollan estudiantes en un curso de precálculo mediado por software matemático interactivo [Study of the mathematical processes that students develop in a pre-calculus course mediated by interactive mathematical software]. Vicerrectoría de Investigación y Extensión, Universidad Industrial de Santander.

Rigo, M., Rojano, M. T., \& Pluvinage, F. (2011). Las prácticas de justificación en el aula de matemáticas [Justification practices in the math classroom]. PNA, 5(3), 93-103.

Rueda, N. (2016). Habilidades cognitivas asociadas al proceso de representación de fenómenos de variación [Cognitive skills associated with the representation process of variation phenomena] (Unpublished master's thesis). Universidad Industrial de Santander, Colombia.

Stylianides, A. J., \& Stylianides, G. J. (2013). Seeking research-grounded solutions to problems of practice: Classroom-based interventions in mathematics education. ZDM - The International Journal on Mathematics Education, 45(3), 333-341. https:// doi.org/10.1007/s11858-013-0501-y

Toulmin, S. E. (2003). The uses of argument (updated edition of the 1958 book). Cambridge University Press.

\section{http://www.ejmste.com}

